\title{
Optimal Aggregate Blending For Highway works
}

\author{
AbdelRazek AabuolNour, Essam Sharaf, Medhat Youssef
}

\begin{abstract}
In many situatioa in highway sub-base, base and surface course construction, the gradation of a single soil does not meet the specification. The problems of material size variance led to need to combining two or more aggregate having different gradation to produce an aggregate blend that meets specific gradation, design, and cost requirements. The design requirements include fineness modulus, plasticity index and specific gravity.... etc. The task of this work is to design an economical model for highway aggregate blending. This model beside satisfying specific gradation and design requirements; also achieve minimum cost for aggregate blend. The model representing this task is formulated as Linear Goal Programming problem with multi-objective and different system constraints. Using a special computer package "Manager", the optimum proportions of aggregates blend that satisfy specific gradation, design and cost requirei ents was obtained. The model considered in this study demonstrates how to achieve multiple and sometimes conflict inanagerial objectives. The procedure is very simple and can be applied to any number of aggregates
\end{abstract}

